\title{
The Flash Crash Of May 2010: Accident Or Market Manipulation?
}

Chris Rose, Capella University, USA

\begin{abstract}
On May 6th., 2010, the Dow fell about a thousand points in a half hour and Wall Street lost $\$ 800$ billion of value. Some claim that it was just an isolated incident and there was nothing nefarious but with the majority of trading being done by electronic exchanges and with the increase in High Frequency Trading, evidence is emerging that the crash just might have been a case of deliberate manipulations of the market.
\end{abstract}

Keywords: Flash crash; market manipulation; SEC; NYSE

\section{BACKGOUND}

Q)

tock markets today are very different from the first organized stock exchange, which was created in 1792 at Wall Street, New York. There a small group of financial leaders signed an agreement on fees, rules and regulations that would apply in transactions. Every day securities were auctioned and the seller paid a commission on each stock or bond sold. These trades took place in a free and open market where willing buyers and sellers assembled and freely exchanged goods, services and information. Since 1998, the Securities and Exchange Commission (SEC) authorized the formation of electronic exchanges, so that anyone with a computer can compete within established markets such as the New York Stock Exchange (NYSE). About 97\% of NYSE trades today are executed by computers on electronic communication networks (ECNs) which in the last decade have quickly replaced traders, trading on floors as the main global venue for buying and selling every asset, derivative, and contract (Stokes, 2009).

\section{HIGH-FREQUENCY TRADING}

High-Frequency Trading (HFT) accounts for the majority of trading in stocks, commodities and futures in the United States today. For example, HFT firms, only account for approximately $2 \%$ of the 20,000 or so trading firms that operate in U.S. markets today, but this $2 \%$ account for $73 \%$ of all U.S. equity trading volume with aggregate annual profits of $\$ 21$ billion (Iati, 2009).

These sophisticated trading platforms use a combination of proprietary, secret algorithms and the fastest computer hardware available. They absorb and analyze massive amounts of market data and news and generate millions of trades timed to the millisecond. Throughput and latency are also important in HFT with the standard trick being to get your servers as close to the data source as possible, some servers even being located in the same building as the exchange servers. This is important because since data is roughly travelling at the speed of light, each 186 miles from the exchange servers means an additional millisecond for the data to reach you.

"Flash orders" whereby orders are shown to members of an exchange for a split second before being passed on to the wider market give HFT an advantage, and have become an integral part of HFT. Bigger investors are also moving to "dark pools", where orders are anonymously matched so that traders do not alert the wider market to their intentions. Obviously, this means that stock pricing is not transparent and yet dark pools accounted for $9 \%$ of the US market in 2008 (Grant, 2009). 
MAY 6th. 2010

HFTs have no real interest in companies or industries but instead these mathematicians and computer programmers just see securities as a series of abstract data. "Not only are the markets completely computerized, more than half of the market's volume is churned by computers programmed to spot certain patterns in trading. These machines see stocks not as securities used by companies to raise money, but rather, symbols, numbers and bits that are traded, swapped and exchanged" (Kranz, 2010).These computers mine information flows for minute discrepancies and trade at astonishing speeds. On May 6,19 billion shares were bought and sold; as recently as 1998, 3 billion shares constituted a very busy day.

"On May 6th. 2010, the Standard \& Poor's 500-stock index declined 6.2 percent, from 1,136.16 to 1,065.79, in a 20-minute span - an $\$ 862$ billion paper loss-before recovering to finish down 3.2 percent". The decline began midmorning with concerns that the Greek economic problem was spreading elsewhere in Europe. Sell orders vastly outnumbered buys, and the resulting imbalance worsened over the next hour. "During the period of heaviest selling, starting around 2:30 p.m., the NYSE paused electronic trading in certain stocks and switched to computerized auctions conducted by human traders. This caused electronic sell orders to be rerouted to other trading venues, where there were few, if any, buy orders to absorb them." In the next few hours there was confusion and exchanges actually started to cancel trades in hundreds of stocks, in fact transactions in 295 companies were erased (Thomason, Barrett \& Mehta, 2010).

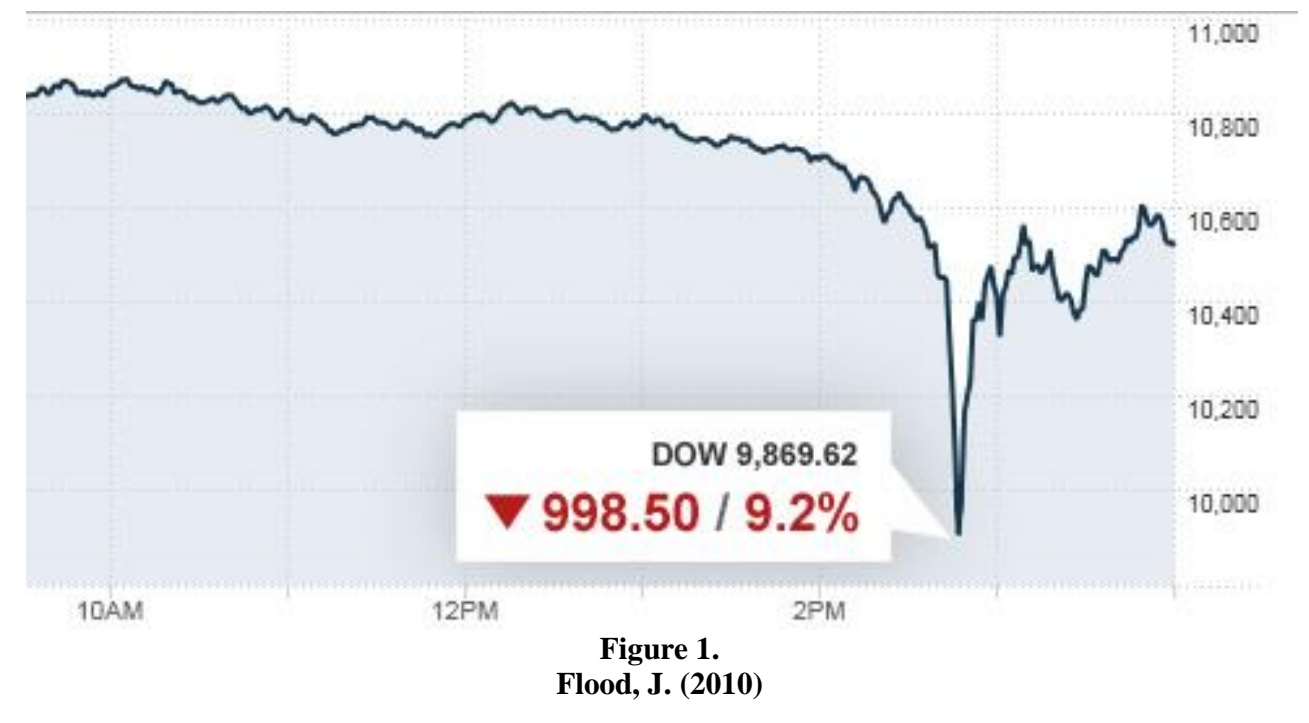

\section{QUOTE STUFFING}

Nine exchanges route orders to NYSE listed stocks and each exchange submits a bid and/or offer price for each stock they wish to trade. The highest bid price is the National Best Bid and the lowest offer price is the National Best Ask. Exchanges compete to become the best bid or offer because obviously they will then get the orders for those stocks. Exchanges also try their best not to cross a market i.e. not bid higher or offer lower because HTFs will immediately execute a buy/offer and capture profit from the small difference. Today, it is extremely rare that a market will be crossed for longer than a few milliseconds (Nanex, 2010a).

In the past traders could mislead investors by conducting fake trades with themselves. For example, in a technique called "painting the tape" a trader enters orders to buy and sell shares in two stocks it controls, giving the false impression there is strong investor interest for the stock at certain prices. This is done to deceive other investors into thinking there is real interest in the stock and lure them into trading based on false information. Painting the tape is illegal, however, modern technology allows traders to do the same thing in a way that is hard for 
regulators to detect. Sophisticated computer systems allow HFTs to post buy and sell prices they have no intention of actually following through on. For instance, a firm might post a bid for a stock showing they want to buy at a certain price. But by the time investors interested in selling at that price get their order to the market, the false buyer yanks the electronic bid in milliseconds, making it difficult to detect (Kranz, 2010).

U.S. regulators investigating the May flash crash are examining the trading practice known as "quote stuffing", in which large numbers of rapid-fire orders to buy or sell stocks are placed and canceled almost immediately. Investors could make trades under the false impression that those orders were legitimate, only to see liquidity disappear and the market move against them when the orders are canceled -- all of this happening in milliseconds. "If traders are flooding the market with orders with the intention of slowing other traders down, then we should consider addressing this under new disruptive trading practices authority" (Rampton, 2010).

Today in HFT systems microseconds matter. If one HFT can process information faster than a competitor that is the winning edge. "If you could generate a large number of quotes that your competitors have to process, but you can ignore since you generated them, you gain valuable processing time. This is an extremely disturbing development, because as more HFT systems start doing this, it is only a matter of time before quote-stuffing shuts down the entire market from congestion" (Nanex, 2010c). On May 6th. one exchange was sending as many as 5,000 quotes for one stock in a single second and there were hundreds of times that a single stock had over 1,000 quotes from one exchange in a single second without any justification for this (Nanex, 2010c).

\section{SUB-PENNY PRICING}

The U.S. Securities and Exchange Commission, which is investigating the crash jointly with the Commodity Futures Trading Commission, is also looking at something called "sub-penny pricing". Sub-penny pricing was introduced by special SEC regulation passed in 2005- SEC Rule 612. This rule was introduced for stock prices under $\$ 1$ and was meant to protect the integrity of the NBBO (National Best Bid and Offer) but with HFT, this rule can now be abused.

It is a violation for this to be used for stocks over $\$ 1$, so suppose you bid $\$ 3.60$ for 1000 shares of Citigroup and you are the National Best Bid (first in line of all the 3.60 bidders). However, a broker/dealer is allowed to use a sub-penny price to provide price improvement to its clients that submit market orders, so the broker is allowed to jump in front of you if they provide "price improvement" to their client with a sub-penny price and buy the 1,000 shares for 3.6001 (Quant Investor's Blog, 2010).

Sub-penny pricing also give HFTs the advantage in dark pools and flash orders. In a dark pool, an algorithm can always add a fraction of a penny to jump in front of the queue and in flash trading when an exchange flashes an order to the HFT, the HFT firm gets a chance to trade against the market order. "When favorable, the HFT firm's computer places a buy order at $\$ 3.6001$ to take the other side of the flashed market order. The 3.6001 quote is never displayed, so this does not violate SEC Rule 612 . Your $\$ 3.60$ buy order, the displayed liquidity, is once again bypassed" (Quant Investor's Blog, 2010).

These practices suggest there are deceptive quotes used in fast moving markets or to alter perceptions about the market. "It is clearly a sign that the modern market is little understood by regulators and investors" (Kim, 2010).

\section{NANEX}

All trade and quote information in New York Stock Exchange (NYSE) and American Stock Exchange (AMEX) listed securities and all SEC-registered exchanges and market centers that trade NYSE or AMEX-listed securities send their trades and quotes to a central consolidator where the Consolidated Quote System (CQS) and Consolidated Tape System (CTS) data streams are produced and distributed. A firm call Nanex follows, tracks and records these streams daily.

The NYSE officially confirmed that there were significant reporting delays from the world's largest stock exchange. "Because of the incredibly high volume that day, there were delays in the reporting on a number of 
stocks," said NYSE spokesman Ray Pollecchia. "We were in the process of updating our programs, and some areas that hadn't yet been updated," were unable to handle the increased load. (Flood, 2010) This lag meant that there were bids on the NYSE that were higher than the lowest offer prices on other exchanges, and offers that were lower than the highest bids on other exchanges.

In Nanex's formulation, the lag occurred because the NYSE bids and offers weren't being time stamped when they were made, but after they got in line behind other quotes and were processed by the NYSE servers, and by the time that whole process was finished and the time stamps applied, the actual prices had already moved on (Flood, 2010). The delay was small enough to cause the NYSE bid to be just slightly higher than the lowest offer price from competing exchanges. This caused sell order flow to route to NYSE -- thus removing any buying power that existed on other exchanges. When these sell orders arrived at NYSE, the actual bid price was lower because new lower quotes were still waiting to exit a queue for dissemination" (Nanex, 2010b).

"If you didn't sell shares during that time then the impact was mostly neutralized very quickly... on the other hand, if you were a day trader with your hands on the keyboard or had a stop loss order that was automatically triggered after it hit that price, then you might have sustained a loss. Many investors who had stop losses with "good 'til cancel" orders saw those positions sold at hefty losses" (Nance-Nash, 2010).

\section{OTHER OCCURANCES}

On June 2, stock in Diebold, a technological services company, experienced a "mini-flash crash" of its own, plunging $35 \%$ and recovering fully in only minutes. Regulators should also check if the drop in Diebold stock was the result of HFTs who can subscribe directly to market data and news feeds and perhaps had programmed faulty logic into their algorithms that are programmed to react to breaking news events (Trading Markets.com 2010).

The Financial Industry Regulatory Authority (FINRA) recently announced that it has censured and fined New York-based Trillium Brokerage Services, LLC, \$1 million for using an illicit HFT strategy and related supervisory failures. Using nine proprietary traders, Trillium "entered numerous layered, non-bona fide market moving orders to generate selling or buying interest in specific stocks. By entering the non-bona fide orders, often in substantial size relative to a stock's overall legitimate pending order volume, Trillium traders created a false appearance of buy- or sell-side pressure" (Durden, 2010).

By doing this Trillium tricked others to enter orders against Trillium's and as soon as they were filled the Trillium traders would then immediately cancel the fake orders. "As a result of this improper high frequency trading strategy, Trillium's traders obtained advantageous prices that otherwise would not have been available to them on 46,000 occasions. Other market participants were unaware that they were acting on the layered, illegitimate orders entered by Trillium traders" (Durden, 2010).

Another big HTF Infinium faces possible civil charges by regulators after its computer ran amok and sparked a frenzied $\$ 1$ surge in oil prices in February. They used an algorithm that was less than a day old to execute a "lead/lag" strategy between an exchange-traded fund called United States Oil Fund, which tracks oil prices, and the U.S. crude benchmark future, West Texas Intermediate. "The algorithm was turned on at 2:26:28 p.m. (Eastern) on February 3, less than four minutes before NYMEX closed floor trading and settled oil prices. It immediately started uncontrollably buying oil futures, Infinium placed 2,000 to 3,000 orders per second before its flooded order router "choked" and was "dead in the water" a few seconds later. The algorithm was shut down five seconds after it was turned on but by then the firm had sent 4,612 "buy limit" orders into the market. It quickly offset the position, in the next few minutes, leaving it with a $\$ 1.03$-million loss. Infinium's burst of buying and selling represented about $4 \%$ of average daily trading volume in the contract, and caused a brief 1.3 percent jump in oil prices, Trading volume spiked nearly eight-fold in less than a minute" (Spicer, 2010).

\section{CONCLUSION}

Eric Hunsader of Nanex says there will be another flash crash and it will be done deliberately. They are using huge volumes to intentionally slow down some aspects of the market to skim profits from clueless 
competitors. His three reasons are:

1. Because the last one was caused on purpose. The average quote volume on the NYSE is 10,000 per second. At one point on May 6, somebody launched 5,000 quotes at the NYSE for the ticker of Public Storage inside of one second. None of those quotes led to a trade. So it is clear that one trader or perhaps more discovered that by blasting the NYSE, they could introduce added latency in the CQS feed. Knowing that most players were looking at a delayed NYSE feed, anybody in the know could make easy arbitrage plays between the NYSE and other exchanges.

2. Because mini flash crashes have happened before. On April 28, for instance, the share prices of Wal-Mart and Procter dipped 50 cents for less than a second. If algorithms had been programmed knowing the dip was coming, profits are fat and easy.

3. The system has shown big delays more than once since then. It seems that whenever the NYSE receives more than 20,000 quotes per second, its CQS feed falls behind (Comstock, 2010).

It is increasingly looking as if the crash of May 6th. was not an accident. By carefully using computer algorithms it has been shown that the markets can be manipulated. With dark pools, flash trading, quote stuffing and sub-penny pricing all being included in the tricks of HFTs, it's no wonder that the market can be manipulated. No one knows when the next flash crash will happen, but it is reasonable to assume that another one will happen. Once again there will be many losers but as usual, a few HFTs will be winners.

\section{REFERENCES}

1. Comstock, C. (August 31,2010) Business Insider. Nanex: There WILL Be Another Flash Crash Because Someone Will Cause It On Purpose. Retrived 9/6/2010 from http://www.businessinsider.com/nanex-therewill-be-another-flash-crash-because-someone-will-cause-it-on-purpose-2010-8

2. Durden, T. (September 9, 2010) Zero Hedge. First HFT Casualty As Finra Fines Trillium $\$ 1$ Million For Quote Stuffing And General Market Manipulation (Again). Retrieved 9/14/2010 from http://www.zerohedge.com/article/first-hft-casualty-finra-fines-trillium-1-million-quote-stuffing-andgeneral-market-manipula

3. Flood, J. (August 10,2010) The Atlantic. NYSE Tech Delays Contributed to the May 6 Flash Crash. Retrieved 9/7/2010 from http://www.theatlantic.com/technology/archive/2010/08/nyse-tech-delayscontributed-to-the-may-6-flash-crash/61987/

4. Grant, J. (July 10, 2009) 'Secretive' firms dominate US share trading. FT.com. Retrieved August 19, 2009 from http://www.ft.com/cms/s/a5f03366-6d69-11de-8b1900144feabdc0,Authorised=false.html?_i_location=http $\% 3 \mathrm{~A} \% 2 \mathrm{~F} \% 2 \mathrm{Fwww} . \mathrm{ft} . \mathrm{com} \% 2 \mathrm{Fcms} \% 2 \mathrm{Fs} \% 2 \mathrm{~F} 0 \% 2 \mathrm{~F}$ a5f03366-6d69-11de-8b19-00144feabdc0.html\%3Fnclick_check\%3D1\&_i_referer=\&nclick_check=1

5. Iati, R. (July 10,2009) The Real Story of Trading Software Espionage. Advanced Trading. Retrieved August 19, 2009 from http://advancedtrading.com/algorithms/showArticle.jhtml?articleID=218401501\#undefined

6. Kim, J. (September 2, 2010) SEC looks at 'quote stuffing' and subpenny pricing. FierceFinanceIT. Retrived 9/5/2010 from http://www.fiercefinanceit.com/story/sec-looking-quote-stuffing-and-subpennypricing/2010-09-02

7. Krantz, M. (2010) Computerized stock trading leaves investors vulnerable. Retrieved 8/2/2010 from http://www.usatoday.com/money/markets/2010-07-09-wallstreetmachine08_CV N.htm

8. $\quad$ Nance-Nash, S. (May 20,2010) Daily Finance. ETF Lessons From the May 6 Flash Crash. Retrieved 9/5/2010 from http://www.dailyfinance.com/story/investing/etf-lessons-may-6-flash-crash/19485343/

9. Nanex, Inc. (2010a) Analysis of the "Flash Crash" Retrieved 9/12/2010 from http://www.nanex.net/20100506/FlashCrashAnalysis_CompleteText.html

10. Nanex, Inc. (2010b) Analysis of the "Flash Crash" Date of Event: 20100506 Part 3, The Evidence Retrieved 9/12/2010 from http://www.nanex.net/20100506/FlashCrashAnalysis_Part3-1.html

11. Nanex ,Inc. (2010C) Analysis of the "Flash Crash" Date of Event: 20100506 Part 4, Quote Stuffing, A Manipulative Device. Retrieved 9/8/2010 from http://www.nanex.net/20100506/FlashCrashAnalysis_Part4-1.html 
12. Quant Investor's Blog, (January 9, 2010) Sub-Penny Pricing: Is it Price Improvement or Front Running? Retrieved 9/14/2010 from http://quantinvestor.wordpress.com/2010/01/09/sub-penny-pricing-is-it-priceimprovement-or-front-running/

13. Rampton, R.(September 2, 2010) Reuters. Quote stuffing' a focus in flash crash probe. Retrieved 9/5/2010 from http://www.reuters.com/article/idUSN0220561320100902

14. Spicer, J. (Aug 25, 2010). Reuters. Firm faces civil charges for oil trading mayhem. Retrieved Sept. 3, 2010 from http://www.reuters.com/article/idUSTRE67O2QQ20100825

15. Stokes, J. (April 22, 2009) Why high-performance computing needs financial engineering. Ars Technica. Retrieved August 19, 2009 from http://arstechnica.com/business/news/2009/04/why-processors-need-highfinance.ars

16. Thomasson, L., Barrett, P. and Mehta. N. (2010) Bloomberg Businessweek. Retrieved 9/2/2010 from http://www.msnbc.msn.com/id/37274616

17. TradingMarkets.com (June 17, 2010). Kaufman: Evidence Shows May 6 Flash Crash "No Isolated Event". Retrieved 0/12/2010 from http://www.tradingmarkets.com/news/press-release/dbd kaufman-evidenceshows-may-6-flash-crash-no-isolated-event--990110.html 